\title{
Estimasi Densitas Tangkasi (Tarsius tarsier) di Luar Kawasan Hutan Hujan Tropis Dataran Rendah Sulawesi Utara Berdasarkan Sampling Duet Call
}

\author{
Indra Polii a*, Saroyo a, Lalu Wahyudi a, Beivy J. Kolondam a \\ aJurusan Biologi, FMIPA, Unsrat, Manado
}

\begin{tabular}{|c|c|}
\hline KATA KUNCI & A B STR A K \\
\hline $\begin{array}{l}\text { Tarsius tarsier } \\
\text { densitas } \\
\text { hutan dataran tinggi } \\
\text { mangrove } \\
\text { semak }\end{array}$ & $\begin{array}{l}\text { Telah dilakukan penelitian tentang densitas tangkasi (Tarsius tarsier) di } \\
\text { luar kawasan hutan tropis dataran rendah Sulawesi Utara berdasarkan } \\
\text { sampling duet call dengan tujuan untuk membandingkan densitasnya } \\
\text { pada beberapa tipe habitat. Penelitian dilaksanakan di Kelurahan } \\
\text { Batuputih untuk habitat pertanian, mangrove, dan semak; serta Gunung } \\
\text { Klabat untuk habitat hutan dataran tinggi. Waktu penelitian dari bulan Mei } \\
\text { sampai Juli } 2013 \text {. Metode penelitian didasarkan pada sampling } \\
\text { berdasarkan duet call dengan plot berbentuk lingkaran. Hasil penelitian } \\
\text { menunjukkan densitas tangkasi ialah: } 2,94 \text { ekor/ha pada hutan dataran } \\
\text { tinggi; } 1,60 \text { ekor/ha pada areal pertanian; } 7,66 \text { ekor/ha pada mangrove; } \\
\text { dan } 8,17 \text { ekor/ha pada semak. }\end{array}$ \\
\hline
\end{tabular}

\section{K E Y W O R D S}

Tarsius tarsier

density

highland forest

mangrove

shrub

\begin{abstract}
A B S T R A C T
A research about density of tangkasi (Tarsius tarsier) at the outside of lowland forest habitat in North Sulawesi has conducted to compare their density at several habitats based on the duet call. Research was done in Batuputih for farming area, mangrove, and shrub habitats and in Klabat Mountain for highland forest habitat. Time of research was May to July 2013. Method used was based on duet call sampling with circle plots. Results of this research were: density of tangkasi was 2.94 individuals/ha at highland forest, 1.60 individuals/ha at farming area, 7.66 individuals/ha at mangrove; and 8.17 individuals/ha at shrub.
\end{abstract}

\section{Pendahuluan}

Tarsius tarsier dalam bahasa lokal disebut tangkasi (Minahasa), ngasi (Sulawesi Tengah), Tanda bona passo (Wana), Podi (Tolaki), Wengu (Mornene) merupakan spesies primata endemik Sulawesi. Jenis ini merupakan satu dari beberapa spesies Tarsius di Sulawesi. Sampai sekarang teridentifikasi beberapa spesies, yaitu T. spectrum, Tarsius sangiriensis, Tarsius pumilis, Tarsius dentatus, Tarsius pelengensis, Tarsius laring, dan Tarsius sp. (Shekelle, 2008).

Tarsius tarsier (Tarsius spectrum) merupakan primata endemik Sulawesi selain enam spesies lainnya (Shekelle, 2008). Distribusi Tarsius spectrum tersebar dari Sulawesi Utara hingga ke Sulawesi Selatan serta pulau-pulau satelitnya, seperti Pulau Suwu, Pulau Selayar, dan Pulau Peleng (Supriatna \& Wahyono, 2000). Tangkasi merupakan salah satu primata terkecil nocturnal. Panjang kepala dan badannya sekitar $117 \mathrm{~mm}$, ekor sepanjang kurang lebih $241 \mathrm{~mm}$, dan bobot tubuh sekitar 108 gram. Telinga dan matanya besar, kepala bulat dan berleher pendek. (Anonimus, 2001; Wright et al., 2003).

Tangkasi menempati habitat hujan tropis primer dan sekunder, semak belukar, hutan mangrove, dan dataran tinggi sampai $1300 \mathrm{~m} \mathrm{dpl}$ (Supriatna dan Wahyono, 2000). Di CA Tangkoko-

*Corresponding author: Jurusan Biologi FMIPA UNSRAT, Jl. Kampus Unsrat, Manado, Indonesia 95115; Email address: indra.polii@yahoo.com Published by FMIPA UNSRAT (2016) 
Batuangus, spesies ini mempunyai daerah jelajah seluas 1,6 - 4,1 ha, dengan rata-rata pada jantan 3,1 ha dan pada yang betina 2,3 ha (Gursky, 1998a). Hewan ini keluar dari tempat tidurnya dan melakukan penjelajahan selama malam hari terutama untuk mencari makanan. Sebelum matahari terbit, kelompok tangkasi akan kembali ke tempat tidurnya yang ditandai dengan duet call (Kinnaird, 1997). Tangkasi memakan berbagai jenis serangga seperti belalang, kepik, kumbang, ngengat, kecoa (Supriatna \& Wahyono, 2000).

Struktur sosial tangkasi bervariasi dari sepasang sampai multimale-multifemale group (Rowe, 1996), Bahkan juga soliter (Gursky, 2000b). Tempat tidur spesies ini di Cagar-Alam TangkokoBatuangus-DuaSuara adalah beringin (Ficus spp.), baik yang tumbuh sendiri atau yang sedang menumpang pada inangnya (Gursky, 1998). Hasil penelitian Saroyo (2008) disimpulkan bahwa tangkasi memiliki beberapa jenis lokasi tempat tidur dengan pemilihan didasarkan pada keamanan dari serangan predator dan perlindungan dari pengaruh alam yang kurang menguntungkan; sosialisasi bervariasi dari soliter sampai multimale-multifemale.

Jenis ini dilindungi oleh Pemerintah Republik Indonesia (Noerdjito \& Maryanto, 2001), masuk dalam Appendix II CITES, serta dikategorikan sebagai spesies dengan resiko rendah (lower risk) menurut IUCN yang pada saat ini direkomendasikan menjadi rentan (vulnerable) (Gursky et al., 2008). Berdasarkan Peraturan Pemerintah Nomor 7 Tahun 1999, Tangkasi merupakan hewan yang dilindungi.

Penurunan populasi merupakan akibat dari kegiatan seperti pengurangan habitat dan penangkapan untuk binatang peliharaan (Supriatna \& Wahyono, 2000). Kini mereka menempati kawasan konservasi sebesar 5.852 ha di berbagai daerah di Sulawesi. Berdasarkan penelitian pendahuluan, Tangkasi banyak dijumpai di luar kawasan hutan, misalnya perkebunan dan biasanya mereka menggunakan rumpun bambu sebagai tempat tidurnya.

Di Cagar Alam Tangkoko-BatuangusDuaSudara, spesies ini mempunyai daerah jelajah seluas 1,6 - 4,1 ha, dengan rata-rata pada jantan 3,1 ha dan pada yang betina 2,3 ha (Gursky, 1998a). berdasarkan penelitian Saroyo (2008), Jumlah individu dalam satu tempat tidur berkisar dari 1 sampai 9 individu dengan rata-rata $4 \pm 2,45$ individu dan modusnya 3.

Tarsius tarsier yang tersebar dari Sulawesi Utara hingga ke Sulawesi Selatan serta pulau-pulau sekitarnya seperti pulau Suwu, pulau Selayer, dan pulau Peleng, sama seperti satwa liar endemik lainnya mengalami ancaman terhadap kepunahan. Spesies ini berdasarkan CITES (Convention on International Trade in Endangered Spesies of Wild Fauna and Flora) tahun 2010 termasuk dalam Appendix II dan dalam reed list IUCN (International Union for Conservation of Nature) tahun 2011 termasuk dalam kategori rentan (vulnerable), hal ini disebabkan oleh beberapa faktor antara lain pengrusakan habitat serta perburuan yang tidak terkontrol (Anonimus, 2001).

Selain hidup pada habitat hutan hujan trois dataran rendah, tangkasi juga ditemukan pada beberapa tipe habitat lainnya, antara lain daerah pertanian, mangrove, semak, serta hutan dataran tinggi (>500 m dpl). Tetapi informasi tentang densitas pada habitat-habitat tersebut belum pernah ada pengkajian, sehingga perlu untuk dilakukan penelitian.

\section{Metode}

\subsection{Tempat dan Waktu Penelitian}

Penelitian dilaksanakan dari bulan April-Mei 2013 diluar kawasan hutan hujan tropis dataran rendah sulawesi utara dengan lokasi 4 tipe habitat seperti disajikan pada Tabel 1.

Tabel 1. Lokasi Penelitian

\begin{tabular}{|c|l|l|}
\hline No & \multicolumn{1}{|c|}{ Tipe Habitat } & \multicolumn{1}{c|}{ Lokasi } \\
\hline 1 & $\begin{array}{l}\text { Hutan dataran tinggi } \\
(>500 \mathrm{~m} \mathrm{dpl})\end{array}$ & Gunung Klabat \\
\hline 2 & Pertanian & Batuputih \\
\hline 3 & Mangrove & Batuputih \\
\hline 4 & Semak & Batuputih \\
\hline
\end{tabular}

\subsection{Alat dan Bahan}

Alat dan bahan yang digunakan dalam penelitian ini ialah: buku panduan lapangan, pita transek, GPS (alat penerima), alat perekam, kompas, senter, spidol permanen, peta lokasi penelitian, jam, meteran, hand counter, dan alat tulis menulis.

\subsection{Prosedur Penelitian}

Lokasi penelitian diambil pada beberapa tipe habitat di luar kawasan hutan hujan tropis dataran rendah Sulawesi utara. Habitat yang dipilih yaitu hutan mangrove, semak, pertanian, dan hutan dataran tinggi (>500m dpl). Jumlah plot sampling setiap tipe vegetasi adalah 20 sehingga keseluruhan plot berjumlah 80 .

Metode yang dilakukan sesuai dengan sampling berbentuk lingkaran dengan radius $100 \mathrm{~m}$. Setiap tipe habitat diambil 20 titik sampel berbentuk lingkaran (Hutan dan Pantai), sisi $50 \mathrm{~m}$ (Mangrove) dan $25 \mathrm{~m}$ (Semak). Metode sampling berdasarkan duet call dilakukan dengan mengkombinasikan beberapa metode perhitungan populasi yaitu metode line transect sampling, point count, dan call count. Metode ini pada dasarnya merupakan metode estimasi populasi yang memanfaatkan vokalisasi yang dikeluarkan oleh tangkasi.

Pengunaan duet call dalam estimasi densitas tangkasi didasarkan pada asumsi-asumsi, antara lain pertama, satu duet call mewakili satu kelompok serta individu soliter diabaikan. Kedua, tangkasi selalu menggunakan duet call pada pagi hari. 
Pengambilan sampel menggunakan bentuk lingkaran radius $100 \mathrm{~m}$, radius $50 \mathrm{~m}$ dan $25 \mathrm{~m}$ yang akan diaplikasikan dalam area penelitian. Pengambilan data dilakukan secara sistematik berdasarkan jalur-jalur dalam blok kuadran. Model metode sampling berdasarkan duet call yang dilakukan disajikan dalam Gambar 1.

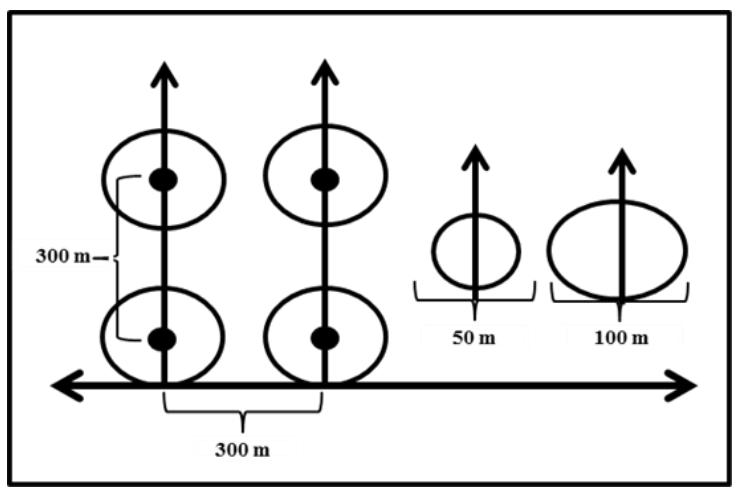

Gambar 1. Model plot lingkaran pada metode sampling (Catatan: Digunakan 3 plot yaitu radius 50, 100 dan $25 \mathrm{~m}$. Plot sampling ditempatkan pada setiap jalur transek dengan jarak antara plot $300 \mathrm{~m}$ ).

Pengambilan data dilakukan satu kali dalam sehari yaitu pukul 05.00-06.00 pada setiap titik pengamatan dalam transek. Pengambilan data dilakukan secara sistematis berdasarkan titik plot pengamatan dalam setiap jalur kuadran. Cara pengambilan data yaitu peneliti berdiri dalam titik pengamatan sambil mengadakan pengamatan kemudian mencatat jumlah duet call dalam radius $100 \mathrm{~m}$ dari titik pengamatan. Setiap terdengar duet call dilakukan pencatatan jumlah duet call, waktu pengamatan, lokasi plot, dan perkiraan jarak pengamat dengan satwa.

Data dianalisis secara deskriptif dengan menghitung densitas tangkasi pada setiap tipe habitat. Dengan rumus yang digunakan :

Densitas $=\frac{\text { Jumlah Duet Call } \times \text { Rata }- \text { RataUkuranKelompok }}{\text { Luas area sampling }}$

\section{Hasil dan Pembahasan}

Hasil perhitungan densitas tangkasi (Tarsius spectrum) pada setiap tipe habitat disajikan pada Tabel 2. dari tabel tersebut, urutan habitat yang memiliki densitas dari paling rendah sampai paling tinggi ialah pertanian, hutan dataran tinggi, mangrove, dan semak.

Tabel 2. Densitas Tangkasi pada 4 Tipe Habitat

\begin{tabular}{|c|l|l|}
\hline No & \multicolumn{1}{|c|}{ Tipe Habitat } & Densitas (ekor/ha) \\
\hline 1 & $\begin{array}{l}\text { Hutan dataran tinggi } \\
(>500 \mathrm{~m} \mathrm{dpl})\end{array}$ & Gunung Klabat \\
\hline 2 & Pertanian & Batuputih \\
\hline 3 & Mangrove & Batuputih \\
\hline 4 & Semak & Batuputih \\
\hline
\end{tabular}

Penelitian sebelumnya yang dilakukan pada habitat hutan dataran rendah di Cagar Alam Tangkoko-Batuangus diperoleh hasil yang berbeda. Hasil penelitian sebelumnya pada beberapa tipe habitat diperoleh hasil, densitas tangkasi di Cagar Alam Tangkoko-Batuangus ialah 1,89 ekor/ha atau 189 ekor/km² (Saroyo \& Koneri, 2012; Saroyo et al., 2014). Hasil penelitian sebelumnya, densitas tangkasi di Cagar Alam Tangkoko-Batuangus justru mengalami peningkatan. Perkiraan kepadatan populasi tangkasi di Cagar Alam Tangkoko pada tahun 1980 yaitu 70 ekor/km² (MacKinnon \& MacKinnon,1980; Gursky 2000) dan tahun 1997 yaitu 156 ekor/km² (Gursky, 1998a).

Densitas tangkasi paling rendah terdapat pada habitat pertanian. Tipe habitat ini pada lokasi penelitian merupakan perkebunan kelapa yang diselingi vegetasi-vegetasi lainnya. Habitat ini tersusun atas vegetasi antara lain kelapa (Cocos nucifera), aren (Arenga pinnata), kenanga (Cananga odorata), bambu (Bambusa, Gigantochloa), rao (Dracontomelon dao), nantu (Palaquium amboinense), dan bugis hutan (Koodersiodendron pinnatum), sirih hutan (Piper aduncum), kayu bunga (Spathodea campanulata), binunga (Macarangta spp.), pandan (Pandanus spp.), cempaka (Elmerillia tsiampaca), nangka (Artocarpus altilis), pangi (Pangium edule), pisang (Musa sp.), Leea sp., dadap (Erythrina sp.), mahoni (Swietenia macrophylla), linggua (Pterocarpus indicus), jati (Tectona grandis), kayu telur (Alstonia macrophylla), matoa (Pometia pinnata), melinjo (Gnetum gnemon), mengkudu morinda (Morinda citrifolia), Pongamia, dan sebagainya.

Tipe habitat pertanian sering mengalami gangguan, terutama pembersihan lahan oleh petani dengan menggunakan herbisida, pemangkasan, maupun pembakaran. Oleh karena itu, kondisi habitatnya tidak stabil dan tangkasi sering kehilangan sarang dan lokasi pencarian makan. Hasil penelitian tentang karakteristik sarang (Saroyo, 2008), di luar habitat hutan, tangkasi sering menempati rumpun bambu, pelepah aren atau sagu, lubang tanah, dan di bawah serasah sebagai tempat persarangannya. Hasil penelitian Saroyo (2008) disimpulkan bahwa Tangkasi memilih jenis lokasi tempat tidur didasarkan pada keamanan dari serangan predator dan perlindungan dari pengaruh alam yang kurang menguntungkan; sosialitas bervariasi dari soliter sampai multimalemultifemale.

Demikian pula sebagai lokasi mencari makan, areal pertanian yang tidak stabil sering kali bukan merupakan tempat mencari makan yang aman. Jenis ini merupakan primata insektivora yang sebagian besar pakannya ialah serangga. Primata ini termasuk satwa yang hidup di pohon (arboreal) walaupun terkadang sering ditemukan Tangkasi berada di tanah untuk menangkap serangga sebagai makanannya (Wirdateti dan Dahrudin, 2006). 
Habitat hutan dataran tinggi ditempati tangkasi dengan densitas yang lebih tinggi dibandingkan dengan di habitat hutan dataran rendah. Hutan dataran tinggi memiliki keamanan yang lebih baik dibandingkan dengan hutan dataran rendah karena aktivitas manusia yang bersifat merusak lebih kecil. Tangkasi memilih lokasi tempat tidur terutama didasarkan pada keamanan dari serangan predator dan perlindungan dari pengaruh alam yang kurang menguntungkan (Saroyo, 2008).

Hutan ditumbuhi beberapa tipe vegetasi antara lain Hutan ini dicirikan dengan anakan pohon dan pancang yang sangat rapat, serta terdapatnya beberapa tanaman pionir, seperti sirih hutan (Piper aduncum), kayu bunga (Spathodea campanulata), dan binunga (Macaranga). Hutan hujan hujan tropis merupakan ekosistem yang paling kompleks di dunia dan mempunyai keanekaragaman hayati yang paling tinggi. Ekosistem ini mempunyai ciri khas terdapatnya tumbuhan merambat (liana) seperti rotan (Calamus) dan tumbuhan menempel (epifit) seperti anggrek dan tumbuhan paku. Pohon-pohon penyusun ekosistem ini membentuk strata tajuk dan mempunyai kanopi yang sangat tinggi yang dapat mencapai tinggi lebih dari $40 \mathrm{~m}$. Beberapa pohon penting antara lain rao (Dracontomelon dao), nantu (Palaquium amboinense), dan bugis hutan (Koodersiodendron pinnatum).

Pohon yang paling penting untuk sarang Tangkasi ialah beringin pencekik (Ficus). Biji pohon ini dibawa burung, kelelawar, atau monyet dan jatuh bersama kotoran hewan tersebut pada cabang suatu pohon. Biji akhirnya berkecambah dan tumbuh membentuk anakan. Pertumbuhan anakan ini dengan membentuk anyaman akar akan membelit dan mencekik pohon inangnya sampai mati. Jika pohon inang ini telah lapuk, maka akan terbentuk lubang besar di tengah untaian akar beringin sehingga disebut beringin lubang. Beringin menghasilkan buah yang berlimpah yang menjadi sumber makanan bagi banyak spesies burung, kelelawar, dan monyet. Ekosistem yang berbeda di dataran tinggi disusun oleh pohon-pohon yang semakin pendek., bahkan sebelum puncak akan dijumpai pula sedikit padang rumput dan raspberry (Rubus) yang mempunyai rasa seperti buah stroberry. Di puncak, pohon-pohon dibungkus oleh lumut, beberapa jenis anggrek, paku, dan tanaman paling mengesankan yaitu kantung semar (Nepenthes). Kantung semar merupakan tanaman insektivor atau pemakan serangga. Serangga yang terjebak dalam kantungnya akan dicerna secara enzimatis dan zat yang dihasilkan akan diserap sebagai nutrien bagi tanaman kantung semar.

Densitas tangkasi pada tipe habitat mangrove dan semak jauh lebh tinggi dbandingkan dengan densitas pada tipe habitat lainnya. Pada tipe habitat tersebut, selama penelitian merupakan tipe habitat yang paling stabil karena tidak pernah mengalami gangguna oleh aktivitas manusia. Habitat mangrovei tersusun atas vegetasi antara lain api-api (Avicennia sp.), ketapang rawa (Barringtonia racemosa), nipah (Nypa fruticans), sagu (Metroxylon sagu), kayu mas (Nauclea orientalis) yang sangat padat sehingga menyediakan tempat yang aman bagi persarangan dan lokasi pencarian makan bagi tangkasi.

Habitat semak tersusun atas vegetasi antara lain jejarongan (Eupatorium odoratum), tembelekan (Lantana camara), tumbuhan merambat gadung (Dioscorea hispida), juga anakan sirih hutan (Piper aduncum), kayu bunga (Spathodea campanulata), dan bugis hutan (Melia azedarach), serta glagah (Sacharum spontaneum). Habitat ini paling jarang diganggu oleh manusia sehingga juga merupakan lokasi yang aman untuk persarangan dan mencari makan tangkasi. Tangkasi membuat sarang di bawah serasah glagah maupun pada jalinan liana atau rumpun pandan.

\section{Kesimpulan}

Dari hasil dan pembahasan dapat disimpulkan sebagai berikut ini:

1. Densitas tangkasi pada beberapa tipe habitat ialah: hutan dataran tinggi 2,94 ekor/ha, pertanian 1,60 ekor/ha, mangrove 7,66 ekor/ha, dan semak 8,17 ekor/ha.

2. Ukuran densitas tangkasi menunjukan keamanan habitat sebagai lokasi persarangan dan mencari makan tangkasi.

\section{Daftar Pustaka}

Anonimus. 2001. Spectral Tarsier (Tarsius spectrum).

http://www.theprimata.com/tarsius_spectrum. html. Diakses tanggal 24 maret 2011

Anonim, 2013b http://flickriver.com/search/ tangkasi/.[15.03.2013]

Gursky. S. 1998a. Conservation status of the spectral tarsier Tarsius spectrum: Population Density And Home Range Size. Folia Primatologica. Primate Taxonomy. Smithsonian Institution Press. Washington. 191 - 203 pp.

Gursky. S. 1998b. Sociality in the spectral tarsier. Tarsius spectrum. American Journal Primatology. United States. 89 - 101 pp.

Gursky, S. 2000. Effect of Seasonality on the Behavior of an Insectivorous Primate, Tarsius spectrum. Int. J. Primatol. 21 (3): 477-495

Gursky. S. 2006. Associations Between Adult Spectral Tarsiers. American Journal Of Physical Anthropology. Department of Anthropology, Texas Adan University, College Station, Texas. 74 - 83 pp.

Gursky, S., M. Shekelle, \& A. Nietsch. 2008. The Conservation Status of Indonesia's Tarsiers. Primates of The Oriental Night: 104-114.

Gursky. S. 2002. “Determinants Of gregariousness in the spectral tarsier (prosimian: Tarsius spectrum)". J. Zoological. 256 (3): 401-410. 
Kinnaird MF. 1997. Sulawesi Utara: Sebuah Panduan Sejarah Alam. Jakarta: Percetakan Redikencana.

Noerdjito M, Maryanto I. 2001. Jenis-Jenis Hayati yang Dilindungi Perundang-Undangan Indonesia. Cibinong: Balitbang Zoologi, Puslitbang BiologiLIPI dan The Nature Conservancy.

Rewo. N. 1996. The Pictorial Guide to the Living Primates. Pogonias Press: East Hampton. New York.
Supriatna. J. dan Wahyono. E. H. 2000. Panduan Lapangan Primata Indonesia. Yayasan Obor Indonesia. Jakarta.

Shekelle. M. 2008. Distribution And Biogeography Of Tarsier. Primates of The Oriental Night. Indonesian Institute Of Sciences Research Center For Biology. Cibinong. 13 - 27 pp.

Shekelle M., Colin G., Stefan M., and Jatna S. 2008. Tarsius tumpara: A New Tarsier Species from Siau Island, North Sulawesi. Primate Conservation Journal. 55 - 64 pp. 